\title{
Thermodynamic disequilibrium of the atmosphere in the context of global warming
}

\section{Citation}

Huang, Junling, and Michael B. McElroy. 2015. “Thermodynamic Disequilibrium of the Atmosphere in the Context of Global Warming." Climate Dynamics (March 18). doi:10.1007/ s00382-015-2553-x.

\section{Published Version}

doi:10.1007/s00382-015-2553-x

\section{Permanent link}

http://nrs.harvard.edu/urn-3:HUL.InstRepos:14344481

\section{Terms of Use}

This article was downloaded from Harvard University's DASH repository, and is made available under the terms and conditions applicable to Open Access Policy Articles, as set forth at http:// nrs.harvard.edu/urn-3:HUL.InstRepos:dash.current.terms-of-use\#OAP

\section{Share Your Story}

The Harvard community has made this article openly available.

Please share how this access benefits you. Submit a story.

\section{Accessibility}


3 Junling Huang

4 School of Engineering and Applied Sciences, Harvard University, 29 Oxford Street, Cambridge,

5 Massachusetts, 02138, USA

6 John F. Kennedy School of Government, Harvard University, 79 John F. Kennedy Street,

7 Cambridge, Massachusetts, 02138, USA

8

$9 \quad$ Michael B. McElroy

10 School of Engineering and Applied Sciences, Harvard University, 29 Oxford Street, Cambridge,

11 Massachusetts, 02138, USA

12

13 Corresponding author: Junling Huang

14 email: junling_huang@ post.harvard.edu

15 phone: $617-955-6282$

16

17

18

19

20

21

22

23 


\section{Abstract}

25 The atmosphere is an example of a non-equilibrium system. This study explores the relationship 26 among temperature, energy and entropy of the atmosphere, introducing two variables that serve

27 to quantify the thermodynamic disequilibrium of the atmosphere. The maximum work, $W_{\max }$, 28 that the atmosphere can perform is defined as the work developed through a thermally reversible 29 and adiabatic approach to thermodynamic equilibrium with global entropy conserved. The

30

31

32

33

34

35

36

37

38

39

40

41

42

43

44

45

46 maximum entropy increase, $(\Delta S)_{\max }$, is defined as the increase in global entropy achieved through a thermally irreversible transition to thermodynamic equilibrium without performing work. $W_{\max }$ is identified as an approximately linear function of $(\Delta S)_{\max }$. Large values of $W_{\max }$ or $(\Delta S)_{\max }$ correspond to states of high thermodynamic disequilibrium. The seasonality and long-term historical variation of $W_{\max }$ and $(\Delta S)_{\max }$ are computed, indicating highest disequilibrium in July, lowest disequilibrium in January with no statistically significant trend over the past 32 years. The analysis provides a perspective on the interconnections of temperature, energy and entropy for the atmosphere and allows for a quantitative investigation of the deviation of the atmosphere from thermodynamic equilibrium.

Keywords: thermodynamic disequilibrium, energy, entropy, temperature, global warming 
8

\section{Introduction}

Most phenomena in the atmosphere are characterized by thermodynamic irreversibility and evolve in time with increases in entropy. The circulation is maintained by the instability of the atmospheric system, and this question has been studied from a variety of different perspectives. Lorenz (1955) presented the Lorenz Energy Cycle (LEC) theory explaining the energetics of atmosphere mainly from a mechanical perspective with kinetic energy produced at the expense of available potential energy $(A P E)$, a measure of the instability of the atmosphere. A number of other groups have sought to address the question from a thermodynamic perspective focusing on the budget of atmospheric energy and entropy (e.g. Coleman and Greenberg 1967; Dutton 1973; Paltridge 1975; Livezey and Dutton 1976; Peixoto et al. 1991; Goody 2000; Paltridge 2001; Pauluis and Held 2002a, 200b; Ozawa 2003; Romps 2008; Lucarini et al. 2011; Bannon 2005; Bannon 2012; Bannon 2013; Huang and McElroy 2014, 2015).

Lorenz (1955) defines $A P E$ as the difference in total static energy (internal plus potential) between the current state of the dry air component of the atmosphere and that of an idealized reference state, identified as the state that minimizes the static energy of the dry air component of the atmosphere after a sequence of reversible isentropic and adiabatic transformations with air parcels conserving their potential temperature, $\theta$. The reference state is characterized by horizontal stratification with absolute stability in pressure, potential temperature and height.

For an isentropic and adiabatic adjustment of the mass field, the surface of constant $\theta$ behaves as a material surface. Thus, the average pressure over an isentropic surface, $\tilde{p}(\theta)$, can be quantified based on the relation:

$$
\tilde{p}(\theta)=\iint_{\sigma} p(x, y, \theta) \cdot d x d y / \iint_{\sigma} d x d y
$$


where $\sigma$ is the global area defined by a constant $\theta$ surface and $p(x, y, \theta)$ is the air pressure in an

$70(x, y, \theta)$ coordinate system. When a constant $\theta$ surface intersects the earth's surface $(\theta \leq$ $\left.71 \theta_{\text {surface }}\right), p(\theta)$ is set equal to $p_{\text {surface }}$. During an isentropic and adiabatic rearrangement of 72 mass, $\tilde{p}(\theta)$ is conserved, representing thus the pressure of the reference state. $A P E$ is defined as

$$
A P E=\int(\Phi+\mathrm{I}) \cdot \mathrm{dm}-\int\left(\Phi_{\mathrm{r}}+\mathrm{I}_{\mathrm{r}}\right) \cdot \mathrm{dm}
$$

where $\Phi$ and $\Phi_{\mathrm{r}}$ represent the potential energy and the corresponding reference state of the atmosphere respectively, and $I$ and $I_{r}$ denote the internal energy for the atmosphere and for the corresponding reference state respectively (Peixoto and Oort, 1992).

Fig. 1 presents a schematic illustration of $A P E$, computed based on assimilated meteorological data from the Modern Era Retrospective-analysis for Research and Applications (MERRA). The upper panels display the zonal-average potential temperature, $\theta$, and the zonal-average temperature, $T$, for year 2008. The lower panels present the zonal-average potential temperature, $\theta$, and the zonal-average temperature, $T$, for the associated reference state, computed based on equation (1). According to the LEC theory, the maximum production of kinetic energy corresponds to the expenditure of all of the $A P E$ when the structure of $\theta$ on the upper panel collapses to the structure depicted on the lower panel. The structure of $\theta$ in the reference state (lower panels in Fig. 1) defines the condition of absolute mechanical equilibrium, since the horizontal pressure force has been eliminated and the vertical pressure force is balanced by gravity.

A number of groups have investigated the $A P E$ of the atmosphere based on the LEC theory (Oort 1964; Oort and Yienger 1996; Li et al. 2007; Boer and Lambert 2008; Hernández-Deckers and Storch 2010; Marques et al. 2009; Becker 2009; Marques et al. 2010; Marques et al. 2011; Kim 
91 and Kim 2013). For example, using MERRA data, Kim and Kim (2013) estimated the global

92 averaged $A P E$ as $4.34 \mathrm{MJ} / \mathrm{m}^{2}$ on an annual mean, $4.02 \mathrm{MJ} / \mathrm{m}^{2}$ for the June $\sim$ August (JJA)

93 mean and $4.75 \mathrm{MJ} / \mathrm{m}^{2}$ for the December $\sim$ February (DJF) mean.

94 The reference state defined by Lorenz, although in mechanical equilibrium, is not in thermal 95 equilibrium. The zonal-average temperature, $T$, for the associated reference state in Fig. 1 96 indicates the existence of a vertical temperature gradient. The reference state has the potential to 97 produce additional kinetic energy through a thermodynamically reversible process. According to 98 the second law of thermodynamics, motions of the atmosphere should drive the system towards thermodynamic equilibrium. A thermodynamic equilibrium state requires both mechanical and 100 thermal equilibrium. Fig. 2 presents a schematic illustration of an approach to thermodynamic 101 equilibrium. The lower panels in Fig. 2 display the zonal-average potential temperature, $\theta$, and 102 zonal-average temperature, $T$, appropriate for a thermodynamic equilibrium state with the 103 equilibrium temperature, $T_{e q}$, set equal to $249 \mathrm{~K}$. When the atmosphere reaches thermodynamic 104 equilibrium, it is completely divested of potential to produce kinetic energy.

105 With respect to entropy, the atmosphere is an open system exchanging energy and matter with its 106 surroundings. According to Prigogine (1962) and De Groot and Mazur (2013), the total variation 107 of the entropy of the atmosphere, $d S^{a t m} / d t$, consists of two components: the transfer of entropy 108 across the boundary, $d S_{e}^{a t m} / d t$, and the entropy produced within the system, $d S_{i}^{a t m} / d t$. The 109 majority of the phenomena operational in the atmosphere, such as the frictional dissipation of 110 kinetic energy, are thermodynamically irreversible. Thus $d S_{i}^{a t m} / d t$ is always greater than zero. $111 d S^{a t m} / d t$ can be expressed as:

$$
\frac{d S^{a t m}}{d t}=\frac{d S_{e}^{a t m}}{d t}+\frac{d S_{i}^{a t m}}{d t}
$$


113 Peixoto et al. (1991) provided a comprehensive analysis of the contributions to $d S_{i}^{a t m} / d t$ and $114 d S_{e}^{a t m} / d t$. A relevant question is: if, since time $t_{0}$ the atmosphere had become an isolated 115 system with zero exchange of energy and matter exchange with its environment $\left(d S^{a t m}=\right.$ $\left.116 d S_{i}^{a t m}\right)$, how much greater would be the eventual increase in entropy, $\int_{t_{0}}^{\infty} \frac{d S^{a t m}}{d t} \cdot d t$, when the 117 atmosphere had reached thermodynamic equilibrium. Similar to $A P E, \int_{t_{0}}^{\infty} \frac{d S^{a t m}}{d t} \cdot d t$ reflects the 118 thermodynamic disequilibrium of the atmosphere.

119 The maximum entropy increase problem was studied by Coleman and Greenberg (1967) 120 addressing a general fluid system other than specifically the atmosphere. Based on the work of 121 Willard Gibbs $(1873,1875)$, they proposed a thermodynamic equilibrium state for any given 122 fluid system together with the associated equilibrium entropy. They argued that the dynamical 123 implication of the difference between the equilibrium state entropy and the entropy of the given 124 system is "remarkable" because it provides a "stability criterion". In the case of the atmosphere, 125 this difference corresponds to $\int_{t_{0}}^{\infty} \frac{d s^{a t m}}{d t} \cdot d t$ subject to the constraint $\frac{d S_{e}^{a t m}}{d t}=0$.

126 Dutton (1973) extended and applied Coleman and Greenberg's study to the atmosphere, and 127 pointed out that every natural state of the atmosphere corresponds to a maximum entropy state, a 128 motionless, hydrostatic state with the same mass and total energy. And this maximum entropy 129 state is the equilibrium towards which an atmosphere in isolation will naturally tend. Bannon $130(2005,2012,2013)$ reexamined the question of the maximum entropy state and introduced the 131 atmospheric available energy which is defined as a generalized Gibbs function between the 132 atmosphere and an isothermal reference state. The reference atmosphere is in thermal and 133 hydrostatic equilibrium and, thus, is dynamically and convectively "dead". 
Landau and Lifshitz (1980) described an approach to study the thermodynamic disequilibrium problem in an Entropy-Energy Diagram and to quantify the maximum work, $W_{\max }$, and maximum entropy increase, $(\Delta S)_{\max }$, that a conceptual isolated system could perform or achieve. Both variables represent the level of disequilibrium for a conceptual system. Their basic idea and methodology is introduced in section 3 with a simple case for demonstration. In the case of the atmosphere, the atmospheric available energy proposed by Bannon is equivalent to the maximum work concept, though without consideration of the gravitational fractionation of the dry air (Bannon 2013). In this study, we extend and apply Landau and Lifshitz's approach to the atmosphere, investigating the level of thermodynamic disequilibrium for the atmosphere in the context of global warming using assimilated meteorological data from MERRA. The analysis provides a perspective on the relationship among temperature, energy and entropy and allows for a quantitative investigation of the deviation of the atmosphere from thermodynamic equilibrium.

\section{Data}

The study is based on meteorological data from the MERRA compilation covering the period January 1979 to December 2010 (Rienecker 2007). Air temperatures and geopotential heights were obtained on the basis of retrospective analysis of global meteorological data using Version 5.2.0 of the GEOS-5 DAS. We use the standard 3-hourly output available for 42 pressure levels with a horizontal resolution of $1.25^{\circ}$ latitude $\times 1.25^{\circ}$ longitude. The highest pressure level at the top of the atmosphere is $0.1 \mathrm{hPa}$. The global surface temperature anomalies employed in this study are from the Goddard Institute for Space Studies (GISS) (Hansen et al. 2010).

\section{Maximum work and maximum entropy increase problem}

For a thermally isolated system consisting of several components out of thermal equilibrium, 
157 while equilibrium is being established, the system can perform mechanical work. The transition 158 to equilibrium may follow a variety of possible paths. The final equilibrium states of the system 159 represented by its energy and entropy may differ as a consequence. The total work that can be 160 performed as well as the entropy increase that may occur from the evolution of a non161 equilibrium system will depend on the manner in which equilibrium is established. Here, we 162 explore two extreme paths to thermal equilibrium: one consistent with the performance of 163 maximum work, $W_{\max }$; the other corresponding to a maximum increase in entropy, $(\Delta S)_{\max }$.

164 The system performs maximum work when the process of reaching thermal equilibrium is 165 reversible. Fig. 3 provides the simplest case with the thermally isolated system consisting of only 166 two components. When the hot component at temperature $T_{\text {hot }}$ loses an amount of energy $167 Q_{h}=-T_{h o t} \delta S_{\text {hot }}$, where $\delta S_{h}$ is the decrease in entropy for the hot component, the cold 168 component at temperature $T_{\text {cold }}$ gains energy $Q_{c}=T_{\text {cold }} \delta S_{c}$, where $\delta S_{c}$ is the entropy increase 169 for the cold component. If the process is reversible, then $\delta S_{c}+\delta S_{h}=0$ and the work produced 170 in the process is equal to $Q_{h}-Q_{c}$. As the reversible process continues, $T_{h o t}$ and $T_{\text {cold }}$ converge 171 to an equilibrium temperature $T_{e q}^{S}$, with the superscript " $S$ " denoting zero entropy change, and 172 the thermally isolated system reaches thermal equilibrium with work output $W_{\max }$. In this study, 173 the transition to thermal equilibrium with $W_{\max }$ is identified as Evolution 1.

174 The system achieves $(\Delta S)_{\max }$ when the process of reaching thermal equilibrium is totally 175 irreversible and the internal energy remains constant. Fig. 4 provides the simplest case for this 176 with energy transfer, $Q$, occurring directly between the components without performing any 177 work. The process is thermally irreversible, and the entropy of the combination of the two 178 components increases by $Q\left(1 / T_{\text {cold }}-1 / T_{\text {hot }}\right)$. As the energy transfer continues, $T_{\text {hot }}$ and $T_{\text {cold }}$ 
179 converge to another equilibrium temperature $T_{e q}^{W}$, with the superscript " $W$ " representing the 180 condition where no work is performed and the subscript " $e q "$ defining equilibrium. $T_{e q}^{W}$ is 181 greater than $T_{e q}^{S}$, since zero work is performed on the external medium. Maximum increase in 182 entropy, $(\Delta S)_{\max }$, for the entire system occurs in the end. In this study, the transition to thermal 183 equilibrium with $(\Delta S)_{\max }$ is indicated as Evolution 2.

184 185 186 187 188 189 190 191 192 193

The maximum work and maximum entropy increase can be depicted in an Entropy-Energy Diagram. If a system is in thermal equilibrium, its entropy, $S_{e q}$, and temperature, $T_{e q}$, are functions of its total energy, $E_{e q}$ : namely $S_{e q}=S_{e q}\left(E_{e q}\right)$ and $T_{e q}=T_{e q}\left(E_{e q}\right)$. In Fig. 5 the continuous line defines the behavior of the function $S_{e q}\left(E_{e q}\right)$ in an Entropy-Energy Diagram. For a non-equilibrium system with thermal condition $(E, S)$ corresponding to point $b$ in Fig. 5, the horizontal segment $\Delta E$ represents the work performed as the system approaches equilibrium through Evolution 1 while the vertical segment $\Delta S$ illustrates the increase in entropy associated with Evolution 2. Consequently $T_{e q}\left(E_{e q}\right)$ at point $a$ corresponds to $T_{e q}^{W}$, and $T_{e q}\left(E_{e q}\right)$ at point $b$ corresponds to $T_{e q}^{S}$. The maximum work, $W_{\max }$, and the maximum entropy increase, $(\Delta S)_{\max }$, reflect the magnitude of the thermodynamic disequilibrium of a non-equilibrium system: if the isolated system is further removed from equilibrium, $W_{\max }$ and $(\Delta S)_{\max }$ are increased; and viceversa.

\section{Ideal gas in a gravitational field}

In a uniform gravitational field with height represented by $z$, the potential energy, $u$, of a molecule is given by $u=m g z$, where $m$ is the mass of a molecule and $g$ is the gravitational acceleration. The distribution of density for a system consisting of an ideal gas at thermodynamic equilibrium is given by the barometric formula: 


$$
\rho(\vec{r})=\rho_{0} e^{-m g z /\left(k_{B} \cdot T_{e q}\right)}
$$

202 where $\rho_{0}$ is the mass density at level $z=0, T_{e q}$ is the equilibrium temperature and $k_{B}$ is the 203 Boltzmann constant. The pressure in equilibrium, $P_{e q}$, at height $z$ is given by:

$$
P_{e q}(z)=\int_{z}^{\infty} \rho_{0} e^{-m g h /\left(k_{B} T_{e q}\right)} g \cdot d h
$$

205 or

206

$$
P_{e q}(z)=P_{0} e^{-m g z /\left(k_{B} \cdot T_{e q}\right)}
$$

207 where $P_{0}$ is the pressure at level $z=0$.

208 For a single mole of ideal gas, assuming temperature-independent specific heat, the associated 209 entropy, $S_{m}$, is given by:

$$
S_{m}=C_{p, m} \ln T-R \ln p+S_{m 0}
$$

211 where $C_{p, m}$ is the molar heat capacity at constant pressure, $R$ is the gas constant, $T$ is the 212 temperature of the gas, $p$ is the pressure and $S_{m 0}$ is a constant of integration. Thus, the total 213 entropy of the system is defined by:

$$
S=\int\left(C_{p, m} \ln T-R \ln p+S_{m 0}\right) \cdot d n
$$

215 and the total static energy (internal plus potential), $E$, is given by:

216

$$
E=\int C_{v, m} T \cdot d n+\int \rho g z \cdot d v
$$

217 where $\mathrm{n}$ is the number of moles, $v$ is volume and $C_{v, m}$ is the molar heat capacity at constant 218 volume.

219 If the initial density distribution of a system follows equation (4), the system consisting of the 220 ideal gas is in thermodynamic equilibrium at $\mathrm{T}_{\text {eq }}$. For a one-dimensional equilibrium system at 221 two temperatures $T_{e q}^{1}$ and $T_{e q}^{2}$, Dutton (1972) proved that the associated equilibrium energies, $E_{e q}^{1}$, 
222

223

224 Thus:

225

226

227

228

229

232

230

$E_{e q}^{2}$ and the equilibrium entropies $S_{e q}^{1}, S_{e q}^{2}$ are related by:

$$
S_{e q}^{2}-S_{e q}^{1}=C_{p, m} \cdot \ln \left(E_{e q}^{2} / E_{e q}^{1}\right) \cdot \int d n
$$

For the case where $\Delta \mathrm{T}_{\mathrm{eq}} \rightarrow 0$ and $\ln (1+\mathrm{x}) \sim \mathrm{x}(\mathrm{x}<<1)$,

$$
S_{e q}\left(\mathrm{~T}_{\mathrm{eq}}+\Delta \mathrm{T}_{\mathrm{eq}}\right)-S_{e q}\left(\mathrm{~T}_{\mathrm{eq}}\right) \approx C_{p, m} \cdot \frac{E_{e q}\left(\mathrm{~T}_{\mathrm{eq}}+\Delta \mathrm{T}_{\mathrm{eq}}\right)-E_{e q}\left(\mathrm{~T}_{\mathrm{eq}}\right)}{E_{e q}\left(\mathrm{~T}_{\mathrm{eq}}\right)} \cdot \int d n
$$

It follows that

$$
S_{e q}\left(\mathrm{~T}_{\text {eq }}+\Delta \mathrm{T}_{\text {eq }}\right)-S_{e q}\left(\mathrm{~T}_{\text {eq }}\right)=C_{p, m} \cdot \ln \left(E_{e q}\left(\mathrm{~T}_{\text {eq }}+\Delta \mathrm{T}_{\text {eq }}\right) / E_{e q}\left(\mathrm{~T}_{\text {eq }}\right)\right) \cdot \int d n
$$

$$
\frac{E_{e q}\left(\mathrm{~T}_{\mathrm{eq}}+\Delta \mathrm{T}_{\mathrm{eq}}\right)-E_{e q}\left(\mathrm{~T}_{\mathrm{eq}}\right)}{S_{e q}\left(\mathrm{~T}_{\mathrm{eq}}+\Delta \mathrm{T}_{\mathrm{eq}}\right)-S_{e q}\left(\mathrm{~T}_{\mathrm{eq}}\right)} \approx \frac{E_{e q}\left(\mathrm{~T}_{\mathrm{eq}}\right)}{C_{p, m} \int d n}
$$
Under thermodynamic equilibrium conditions, $E_{e q}\left(\mathrm{~T}_{\mathrm{eq}}\right)=C_{p, m} \int T_{e q} d n$ (Peixoto and Oort, 1992). Thus:

$$
\frac{\partial E_{e q}}{\partial S_{e q}}=T_{e q}
$$

If the initial density distribution of a system departs from equation (4), the system consisting of

234 the ideal gas will not be in equilibrium. It can approach equilibrium through a number of paths 235 including evolution 1 depicted in Fig. 3 and evolution 2 depicted in Fig. 4 Consequently, 236 maximum work, $W_{\max }$, is produced by the system if the transition to equilibrium at temperature $237 T_{e q}^{S}$ is reversible (evolution 1 in Fig. 3), namely $\Delta S=0$. The maximum work, $W_{\max }$, is equal to $238 \Delta E$, according to the first law of thermodynamics. $W_{\max }$ may be expressed as: 


$$
W_{\text {max }}=\int C_{v, m}\left(T-T_{e q}^{S}\right) \cdot d n+\int\left(\rho-\rho_{e q}^{S}\right) g z \cdot d v
$$

240 where $\rho_{e q}^{S}(z)=\rho_{0}^{S} e^{-m g z /\left(k_{B} \cdot T_{e q}^{S}\right)}$. Reflecting the principle of mass conservation, $\int \rho_{e q}^{S} \cdot d v=$ $241 \int \rho \cdot d v$, or equivalently, $\rho_{0}^{S}=\left(\int \rho \cdot d v\right) /\left(\int e^{-m g z /\left(k_{B} \cdot T_{e q}^{S}\right)} \cdot d v\right)$.

242 Similarly, the system achieves maximum entropy increase if the transition to equilibrium at 243 temperature $T_{e q}^{W}$ is thermally irreversible and produces no work (evolution 2 in Fig. 4), $\Delta E=0$.

244 And the maximum entropy increase may be expressed as:

$$
(\Delta S)_{\max }=\int\left[C_{p, m}\left(\ln T_{e q}^{W}-\ln T\right)-R\left(\ln P_{e q}^{W}(z)-\ln p\right)\right] \cdot d n
$$

246 where $P_{e q}^{W}(z)=P_{0}^{W} e^{-m g z /\left(k_{B} \cdot T_{e q}^{W}\right)}$. Because of the principle of mass conservation,

$247 \iint_{\text {surface }} P_{e q}^{W}(z) \cdot d x d y=\iint_{\text {surface }} P \cdot d x d y$. The equilibrium pressure $P_{e q}$ at level $z=0$, 248 namely $P_{0}$, can be computed as:

$$
P_{0}=\iint_{\text {surface }} P \cdot d x d y / \iint_{\text {surface }} e^{-m g h /\left(k_{B} \cdot T_{e q}\right)} \cdot d x d y
$$

where $\mathrm{h}$ is the topographic height.

\section{5. A thermodynamic perspective on the atmosphere}

252 Oxygen $\left(\mathrm{O}_{2}\right)$ occupies $20.95 \%$ by volume of dry air in the atmosphere. Nitrogen $\left(\mathrm{N}_{2}\right)$ accounts 253 for $78.08 \%$. The next two most abundant gases are argon (Ar) (0.93\%) and carbon dioxide $\left(\mathrm{CO}_{2}\right)$ $254(0.04 \%)$. To simplify the calculation in this study we assume that $\mathrm{O}_{2}$ occupies $21 \%$ of dry air, $\mathrm{N}_{2}$ $25578 \%$ and Ar $1 \%$ for well mixed dry air by volume and a constant gravity of $9.8 \mathrm{~m} / \mathrm{s}^{2}$. The molar 256 masses of $\mathrm{O}_{2}, \mathrm{~N}_{2}$ and Ar equal $32 \mathrm{~g} / \mathrm{mol}, 28 \mathrm{~g} / \mathrm{mol}$ and $40 \mathrm{~g} / \mathrm{mol}$ respectively.

257 For one mole of $\mathrm{O}_{2}, \mathrm{~N}_{2}$ and Ar, the associated entropies $S_{m}^{O_{2}}, S_{m}^{N_{2}}$ and $S_{m}^{A r}$ are given by: 


$$
S_{m}^{O_{2}}=C_{p, m}^{O_{2}} \ln T-R \ln P^{O_{2}}+S_{m 0}^{O_{2}}
$$

$$
S_{m}^{N_{2}}=C_{p, m}^{N_{2}} \ln T-R \ln P^{N_{2}}+S_{m 0}^{N_{2}}
$$

$$
S_{m}^{A r}=C_{p, m}^{A r} \ln T-R \ln P^{A r}+S_{m 0}^{A r}
$$

261 where $C_{p, m}^{O_{2}}, C_{p, m}^{N_{2}}$ and $C_{p, m}^{A r}$ represent the molar heat capacities at constant pressure for $\mathrm{O}_{2}, \mathrm{~N}_{2}$ and $262 \mathrm{Ar} ; P^{O_{2}}, P^{N_{2}}$ and $P^{A r}$ denote the partial pressures for $\mathrm{O}_{2}, \mathrm{~N}_{2}$ and Ar; and $S_{m 0}^{O_{2}}, S_{m 0}^{N_{2}}$ and $S_{m 0}^{A r}$ are 263 the related constants of integration. Since $\mathrm{O}_{2}$ and $\mathrm{N}_{2}$ are diatomic gases, $C_{p, m}^{O_{2}}$ and $C_{p, m}^{N_{2}}$ are set 264 equal to $\frac{7}{2} R$. Ar is monatomic gas, thus $C_{p, m}^{A r}$ is equal to $\frac{5}{2} R$. And $R$ is the ideal gas constant and 265 equal to $8.3145 \mathrm{~J} /(\mathrm{mol} \cdot \mathrm{K})$. Since in this study we are interested in changes in entropy, 266 constants of integration are set to zero. The total entropy of dry air, $S_{a t m}$, in the atmosphere may 267 be expressed then as:

$$
S^{a t m}=S^{O_{2}}+S^{N_{2}}+S^{A r}
$$

269 where $S^{O_{2}}=\int\left(C_{p, m}^{O_{2}} \ln T-R \ln P^{O_{2}}\right) d n_{O_{2}}, S^{N_{2}}=\int\left(C_{p, m}^{N_{2}} \ln T-R \ln P^{N_{2}}\right) d n_{N_{2}}$ and $S^{A r}=$ $270 \int\left(C_{p, m}^{A r} \ln T-R \ln P^{A r}\right) d n_{A r}$ respectively.

271 The total static energy of dry air, $E_{a t m}$, is given by:

$$
E^{a t m}=E^{O_{2}}+E^{N_{2}}+E^{A r}
$$

273 where $E^{O_{2}}=\int C_{v, m}^{O_{2}} T \cdot d n_{O_{2}}+\int \rho^{O_{2}} g z \cdot d v, E^{N_{2}}=\int C_{v, m}^{N_{2}} T \cdot d n_{N_{2}}+\int \rho^{N_{2}} g z \cdot d v$ and $E^{A r}=$ $274 \int C_{v, m}^{A r} T \cdot d n_{A r}+\int \rho^{A r} g z \cdot d v$ respectively.

275 For a specific equilibrium temperature, $T_{e q}$, the partial pressures, $P_{e q}^{O_{2}}, P_{e q}^{N_{2}}$ and $P_{e q}^{A r}$, and the 276 densities, $\rho_{e q}^{O_{2}}, \rho_{e q}^{N_{2}}$ and $\rho_{e q}^{A r}$, for $\mathrm{O}_{2}, \mathrm{~N}_{2}$ and Ar in equilibrium can be quantified according to the 277 principle of mass conservation. For example, $\rho_{e q}^{O_{2}}$ can be computed based on $\int \rho_{e q}^{O_{2}} \cdot d v=$ 
$278 \int \rho^{O_{2}} \cdot d v$ and $\rho_{e q}^{O_{2}}=\rho_{0}^{O_{2}} \cdot e^{-m_{O_{2}} g h /\left(k_{B} \cdot T_{e q}\right)}$. Subsequently, the entropy, $S_{e q}^{a t m}$, and the static 279 energy, $E_{e q}^{a t m}$, of the atmosphere in equilibrium at $T_{e q}$ can be computed based on equations (15) 280 and (16).

281 The highest pressure level in the dataset is $0.1 \mathrm{hPa} . \mathrm{S}_{\mathrm{eq}}^{\mathrm{atm}}$ and $\mathrm{E}_{\mathrm{eq}}^{\mathrm{atm}}$ are quantified through 282 integrations from the ocean or land surface to the $0.1 \mathrm{hPa}$ level. Fig. 6 illustrates the behavior of 283 the function $S_{e q}^{a t m}\left(E_{e q}^{a t m}\right)$ with $T_{e q}$ increasing from $100 \mathrm{~K}$ to $500 \mathrm{~K}$. The behavior of $\partial E_{e q}^{a t m} /$ $284 \partial S_{e q}^{a t m}$ as a function of $T_{e q}$ is shown in Fig.7. Reflecting the topographic height of the continents, $285 \partial E_{e q}^{a t m} / \partial S_{e q}^{a t m}$ is approximately equal, but not identical, to $T_{e q}$. When $T_{e q}$ becomes warmer, the 286 air molecules have higher kinetic energy and consequently have greater chances of moving to 287 high altitudes and above the continents. Thus, the process of increasing $T_{e q}$ involves a re288 distribution of air between oceanic and continental regions.

289 In calculating $\left(\mathrm{E}^{\mathrm{atm}}, \mathrm{S}^{\mathrm{atm}}\right)$ for a non-equilibrium real atmosphere, $\mathrm{E}^{\mathrm{atm}}$ and $\mathrm{S}^{\mathrm{atm}}$ are quantified 290 through integrations from the topographic surface to $0.1 \mathrm{hPa}$ level. The thermodynamic condition, $291\left(E^{a t m}, S^{a t m}\right)$, of the atmosphere on May 30, 2002 is identified by point $b$ in the Entropy-Energy 292 Diagram in Fig. 8, below the line of $S_{e q}^{a t m}\left(E_{e q}^{a t m}\right)$, confirming the fact that the atmosphere was 293 out of thermodynamic equilibrium, with the associated $W_{\max }=29.2 \mathrm{MJ} / \mathrm{m}^{2}$ and $(\Delta S)_{\max }=$ $294117 \mathrm{~kJ} /\left(\mathrm{m}^{2} \cdot \mathrm{K}\right)$.

295 The seasonality of the thermodynamic condition, $\left(E^{a t m}, S^{a t m}\right)$, of the atmosphere in an Entropy296 Energy Diagram is plotted in Fig. 9. The loop-shaped seasonality reflects the asymmetric 297 distribution of land with respect to the equator in addition to the seasonally varying earth-sun 298 distance. If the distributions of land in the Northern Hemisphere were the same as in the 
Southern Hemisphere and the earth-sun distance was constant, the thermodynamic condition on June 22 (summer solstice) identified in an Entropy-Energy Diagram should be the same as for December 22 (winter solstice). Similarly, the thermodynamic condition on March 21 (vernal equinox) should overlap that for September 23 (autumnal equinox) (see Fig. 10). The seasonality in Fig. 9 would have been line-shaped with the conditions of June 22 and December 22 on one end, the conditions for March 21 and September 23 on the other.

A greater content of static energy in the atmosphere does not necessarily correspond to higher thermodynamic disequilibrium and vice versa. For example, the total static energy on May 1 is close to that on October 1 . Since the associated total entropy on May 1 is greater than on October 1 , the atmosphere was thermodynamically more stable on May 1.

The seasonalities of $W_{\max }$ and $(\Delta S)_{\max }$ are plotted in Fig. 11. The atmosphere reaches its state of highest thermodynamic disequilibrium in late July with $W_{\max }=31.4 \mathrm{MJ} / \mathrm{m}^{2}$ and $(\Delta S)_{\max }=126 \mathrm{~kJ} /\left(\mathrm{m}^{2} \cdot \mathrm{K}\right)$, its lowest state in mid January with $W_{\max }=27.7 \mathrm{MJ} / \mathrm{m}^{2}$ and $(\Delta S)_{\max }=112 \mathrm{~kJ} /\left(\mathrm{m}^{2} \cdot \mathrm{K}\right) . W_{\max }$ can be approximated as $W_{\max } \approx 248 \mathrm{~K} \cdot(\Delta S)_{\max }$. Large values of $W_{\max }$ are associated with large values of $(\Delta S)_{\max }$, corresponding to high states of thermodynamic disequilibrium. The thermodynamic condition $\left(E^{a t m}, S^{a t m}\right)$ of the atmosphere is close to $S_{e q}^{a t m}\left(E_{e q}^{a t m}\right)$ as depicted by Fig. 8. Thus, $W_{\max } /(\Delta S)_{\max }$ is approximately equal to $\partial E_{e q}^{a t m} / \partial S_{e q}^{a t m}$, and, consequently, to $T_{e q}$.

The long-term variation of $W_{\max }$ from January 1979 to December 2010 is illustrated in Fig. 12. The conspicuous intra-seasonal fluctuation depicted by the red line reflects the strong seasonal variation of the $W_{\max }$. The blue line, computed using a 365-day running average, reflects the existence of an inter-annual variation. Linear regression of the annual mean average over this 
321 period provides a regression slope of $2.4 \mathrm{~J} /\left(\mathrm{m}^{2} \cdot y r\right)$ with $\mathrm{R}^{2}=0.004$, indicating that there is no 322 statistically significant trend in thermodynamic disequilibrium. It is not yet clear what 323 determines the inter-annual variability of $\mathrm{W}_{\max }$. The large scale atmosphere-ocean El Niño 324 Southern Oscillation phenomenon could provide one possible explanation. We would note in this 325 context that the highest peak in $\mathrm{W}_{\max }$ is coincident with the major El Nino event of 1997-1998.

326 The seasonalities of the equilibrium temperatures, $T_{e q}^{S}$ and $T_{e q}^{W}$, are displayed in Fig. 13. $T_{e q}^{W}$ is 327 greater than $T_{e q}^{S}$, reflecting the fact that no work is performed in evolution 2 . Both $T_{e q}^{S}$ and $T_{e q}^{W}$ 328 reach their peak values in late July, corresponding to the highest content of static energy. The 32329 year averaged values for $T_{e q}^{S}$ and $T_{e q}^{W}$ are $248.9 \mathrm{~K}$ and $251.8 \mathrm{~K}$ respectively. The gap between $330 T_{e q}^{S}$ and $T_{e q}^{W}$ reflects the thermodynamic disequilibrium of the atmosphere.

331 In this study, the variation of $T_{e q}^{S}$ is indicated by:

$$
\Delta T_{e q}^{S}=T_{e q}^{S}-248.5 K
$$
and the variation of $T_{e q}^{W}$ is defined by:

$$
\Delta T_{e q}^{W}=T_{e q}^{W}-251.5 K
$$

335 The variation of $T_{e q}^{S}$ and $T_{e q}^{W}$ with the seasonal cycle removed is shown in Fig. 14. The increases 336 of $\Delta T_{e q}^{S}$ and $\Delta T_{e q}^{W}$ generally follow the global surface temperature change, $\Delta T_{\text {surface, }}$, with the 337 correlation between $\Delta T_{e q}^{S}$ and $\Delta T_{\text {surface }}$ equal to 0.87 and correlation between $\Delta T_{e q}^{W}$ and $338 \Delta T_{\text {surface }}$ equal to 0.91 . Thus, as the global surface temperature increased from January 1979 to 339 December 2010, the thermodynamic conditions $\left(E^{a t m}, S^{a t m}\right)$ of the atmosphere on an Energy340 Entropy Diagram moved on a trajectory parallel to the line of $S_{e q}^{a t m}\left(E_{e q}^{a t m}\right)$ in Fig. 8, resulting in 341 increases in $T_{e q}^{S}$ and $T_{e q}^{W}$, with $W_{\max }$ and $(\Delta S)_{\max }$ remaining relatively constant. 


\section{Discussion and Summary}

This study presented an approach for analysis of the interrelations of temperature, energy and entropy of the atmosphere, and proposed two variables, $W_{\max }$ and $(\Delta S)_{\max }$, as measures of the thermodynamic disequilibrium of the atmosphere. $W_{\max }$ is approximately a linear function of $(\Delta S)_{\max }: W_{\max } \approx 248 \mathrm{~K} \cdot(\Delta S)_{\max }$. The annual mean value of $W_{\max }$ was estimated at $29.6 \mathrm{MJ} /$ $\mathrm{m}^{2}$ with $31.0 \mathrm{MJ} / \mathrm{m}^{2}$ for JJA and $28.0 \mathrm{MJ} / \mathrm{m}^{2}$ for DJF. The conservation of mass between the atmospheric system and the isothermal reference is crucial for the quantification method developed in this study.

Based on the same assimilated meteorological dataset as used in this study, Kim and Kim (2013) estimated the global averaged $A P E$ at $4.34 \mathrm{MJ} / \mathrm{m}^{2}$ for the annual mean, $4.02 \mathrm{MJ} / \mathrm{m}^{2}$ for JJA and $4.75 \mathrm{MJ} / \mathrm{m}^{2}$ for DJF. There are considerable differences in the absolute values for APE and $W_{\text {max }}$. Fig. 15 provides a schematic illustration of the relationship between $A P E$ and $W_{\text {max }}$ with point $b$ corresponding to the thermodynamic condition, $\left(E^{a t m}, S^{a t m}\right) . A P E$ is defined as the difference in total static energy between the current state of the dry air component of the atmosphere and that of an idealized reference state corresponding to the minimum content of static energy present following a sequence of reversible isentropic transformations. When the atmosphere fully releases its $A P E$ through a isentropic and adiabatic process to perform mechanical work and reaches the associated reference state, the total value of $S^{\text {atm }}$ should remain constant. On the Entropy-Energy Diagram in Fig. 15, this process corresponds to a thermodynamic transition from point $b$ to point $d$ with entropy conserved. However, the reference state in mechanical equilibrium is not in thermal equilibrium, and the maximum work, $W_{\max }$, has not as yet been completely exerted. Thus, APE corresponding to the $b$-to- $d$ displacement in Fig. 15 should be smaller than $W_{\max }$ corresponding to the $b$-to- $c$ displacement 

in Fig. 15. It follows that $A P E$ may be considered as the mechanical component of $W_{\text {max }}$.

366 For an isothermal well-mixed atmosphere at $250 \mathrm{~K}, W_{\max }$ is quantified to be $1.5 \mathrm{MJ} / \mathrm{m}^{2} \mathrm{using}$ 367 the approach described in Section 4. This quantity, $1.5 \mathrm{MJ} / \mathrm{m}^{2}$, represents the contribution from 368 the gravitational separation of gases to $W_{\max }$ for a real atmosphere. Thus the part of $W_{\max }$ 369 attributed to the vertical temperature contrast can be estimated as $W_{\max }-A P E-1.5 \mathrm{MJ} / \mathrm{m}^{2} \approx$ $370 \quad 23.8 \mathrm{MJ} / \mathrm{m}^{2}$.

371 Fig. 16 presents a schematic illustration of the $d$-to- $c$ displacement in Fig. 15. The upper panels 372 in Fig. 16 display the zonal-average potential temperature, $\theta$, and the zonal-average temperature, $373 T$, appropriate for the associated reference state proposed by Lorenz, with its thermodynamic 374 condition, $\left(E^{a t m}, S^{a t m}\right)$, corresponding to point $d$ in Fig.15. The lower panels display zonal375 average potential temperatures, $\theta$, and zonal-average temperatures, $T$, for the associated 376 thermodynamic equilibrium state with its thermodynamic condition, $\left(E^{a t m}, S^{a t m}\right)$, 377 corresponding to point $c$ in Fig. 15. When the thermally non-equilibrium reference state proposed 378 by Lorenz approaches thermodynamic equilibrium through Evolution 1, the work performed is 379 equal to $\left(W_{\max }-A P E\right)$. While Lorenz's concept of energetics is based on APE that can be extracted through a reversible 381 adiabatic transformation of dry air, his main concern was with the rate for its generation by 382 radiative heating and cooling, and the subsequent dissipation of this energy by mechanically 383 irreversible processes. The fundamental question he addressed was why and how the present 384 strength of the general circulation was determined. The main interest in this paper is to quantify 385 the thermodynamic disequilibrium of the present climate state, although the relationship between $386 \mathrm{~W}_{\max }$ and APE is also investigated. 
387 Considering the long-term variability of $W_{\max }$, as the global surface temperature, $T_{\text {surface }}$, increased from January 1979 to December 2010, the equilibrium temperatures, $T_{e q}^{S}$ and $T_{e q}^{W}$, increased at about the same pace as $T_{\text {surface }}$. Consequently, there was no statistically significant trend in $W_{\text {max }}$ over this interval. It is important to understand how the atmosphere adjusted its thermodynamic structure over this period, including its vertical temperature profile in order to maintain a relatively constant $W_{\max }$. A number of studies pointed out that the lower-tropospheric temperatures have experienced slightly greater warming since 1958 than those at the surface. Lower-stratospheric temperatures have exhibited cooling since 1979 while the tropopause height has increased by 200m between 1979 and 2001 (Randel et al. 2000; Grody et al. 2004; Santer et al. 2004; Simmons et al. 2004; Fu and Johanson 2005; Karl et al. 2006; Vinnikov et al. 2006). It is important to explore the pertinent implications for $W_{\max }$.

The global thermodynamic disequilibrium of the atmosphere was analyzed retrospectively in this study based on the MERRA data. We also estimated the thermodynamic disequilibrium corresponding to the one-dimensional international standard atmosphere (See Supplementary Material). The value of $W_{\max }$ for the one-dimensional international standard atmosphere is 402 estimated at $16.8 \mathrm{MJ} / \mathrm{m}^{2}$. The previous study reported a value of $12.6 \mathrm{MJ} / \mathrm{m}^{2}$ for a $50 \mathrm{~km}$ standard atmosphere (Bannon 2012). The one-dimensional international standard atmosphere 404 doesn't represent the thermodynamics of the time-resolved three-dimensional atmosphere. Thus, there is a difference in the values of $W_{\max }$ between the one-dimensional model and the three 406 dimensional atmosphere. Nevertheless, a relevant question is whether the conclusions reached here may be conditioned by the use of this specific data base. Other datasets including NCEP-1,

408 NCEP-2, ERA-40 and JRA-25 should be employed in future work to compare with the results 409 presented here. 
This study focused on the dry air component of the atmosphere. In the real atmospheric system consisting of dry air and water, its total entropy $S^{\text {total }}$ and total static energy $E^{\text {total }}$, according to thermodynamics, can be expressed as: $S^{\text {total }}=S^{a t m}+S^{H_{2} O}$ and $E^{\text {total }}=E^{a t m}+E^{H_{2} O}$, where $S^{\mathrm{H}_{2} \mathrm{O}}$ and $E^{\mathrm{H}_{2} \mathrm{O}}$ represent the associated entropy and static energy of the water component.

The water component plays an important role in the thermodynamics of the atmosphere, including maintenance of the general circulation (Lorenz 1978). When sunlight reaches the ocean surface, much of the energy absorbed by the ocean is used to evaporate water. Water vapor in the atmosphere acts as a reservoir for storage of heat to be released later. As the air ascends, it cools. When it becomes saturated, water vapor condenses with consequent release of latent heat. Heating is dominated in the tropical atmosphere by release of latent heat. Separate bands of relatively deep heating are observed also at mid-latitudes where active weather systems result in enhanced precipitation and release of latent heat. The condensation and evaporation of water contribute to non-uniform diabatic heating and cooling of the dry air, and, consequently, to the circulation of the atmosphere.

The water component is also an example of a thermodynamic non-equilibrium system. Under thermodynamic equilibrium conditions, liquid and solid water would be totally absent above the ground. The entire process of evaporation from the ocean, followed by condensation to form clouds and precipitation is thermodynamically irreversible. The analytical approach developed here could be used to investigate the thermodynamics of the water component by quantifying the thermodynamic condition, $\left(E^{\mathrm{H}_{2} \mathrm{O}}, S^{\mathrm{H}_{2} \mathrm{O}}\right)$ and the line of $S_{e q}^{\mathrm{H}_{2} \mathrm{O}}\left(E_{e q}^{\mathrm{H}_{2} \mathrm{O}}\right)$ and by calculating $W_{\max }$ and $(\Delta S)_{\max }$ for the water component in an Entropy-Energy Diagram. The water component can further increase the thermodynamic disequilibrium of the moist atmosphere. 


\section{Acknowledgements}

433 The work described here was supported by the National Science Foundation, NSF-AGS-1019134.

434 Junling Huang was also supported by the Harvard Graduate Consortium on Energy and

435 Environment. We acknowledge helpful and constructive comments from Michael J. Aziz and

436 Peter R. Bannon and from the reviewers.

437

438

439

440

441

442

443

444

445

446

447

448

449

450

451

452

453

454 
456 Bannon PR (2005) Eulerian available energetics in moist atmospheres. J Atmos Sci. 457 doi:10.1175/JAS3516.1

458 Bannon PR (2012) Atmospheric Available Energy. J Atmos Sci. doi:10.1175/JAS-D-12-059.1

459 Bannon PR (2013) Available Energy of Geophysical Systems. J Atmos Sci. 460 doi.org/10.1175/JAS-D-13-023.1

461 Becker E (2009) Sensitivity of the upper mesosphere to the Lorenz energy cycle of the 462 troposphere. J Atmos Sci. doi:10.1175/2008JAS2735.1

463 Boer GJ, Lambert S (2008) The energy cycle in atmospheric models. Climate dynamics. 464 doi:10.1007/s00382-007-0303-4

465 Coleman BD, Greenberg JM (1967) Thermodynamics and the stability of fluid motion. Archive 466 for Rational Mechanics and Analysis, 25(5), 321-341.

467 De Groot SR, Mazur P (2013) Non-equilibrium thermodynamics. Courier Dover Publications.

468 Dutton JA (1973) The global thermodynamics of atmospheric motion. Tellus. doi:10.1111/j.2153$469 \quad 3490.1973 . t b 01599 . x$

470 Gibbs JW (1873). A method of geometrical representation of the thermodynamic properties of 471 substances by means of surfaces. Connecticut Academy of Arts and Sciences.

472 Gibbs JW (1878). On the equilibrium of heterogeneous substances. American Journal of Science, 473 (96), 441-458. 
474 Goody R (2000) Sources and sinks of climate entropy. Q J R Meteorol Soc. 475 doi: 10.1002/qj.49712656619

476 Grody NC, Vinnikov KY, Goldberg MD, Sullivan JT, Tarpley JD (2004) Calibration of 477 multisatellite observations for climatic studies: Microwave Sounding Unit (MSU). J Geophys 478 Res. doi: 10.1029/2004JD005079

479 Fu Q, Johanson CM (2005) Satellite-derived vertical dependence of tropical tropospheric 480 temperature trends. Geophys Res Lett. doi: 10.1029/2004GL022266.

481 Hansen J, Ruedy R, Sato M, Lo K (2010) Global surface temperature change. Rev Geophys. 482 doi:10.1029/2010RG000345

483 Hernández-Deckers D, von Storch JS (2010) Energetics Responses to Increases in Greenhouse 484 Gas Concentration. J Climate. doi:10.1175/2010JCLI3176.1

485 Huang J, McElroy MB (2014) Contributions of the Hadley and Ferrel Circulations to the 486 Energetics of the Atmosphere over the Past 32 Years. J Climate. doi:10.1175/JCLI-D-13-00538.1

487 Huang, J, McElroy, MB (2015). A 32-year perspective on the origin of wind energy in a warming 488 climate. Renewable Energy, 77, 482-492.

489 Karl TR, Hassol SJ, Miller CD, Murray WL (2006) Temperature trends in the lower atmosphere. 490 steps for understanding and reconciling differences.

491 Landau LD, Lifshitz EM (1980) Statistical physics, vol. 5. Course of Theoretical Physics, 30. pp $492 \quad 57-65$.

493 Li L, Ingersoll AP, Jiang X, Feldman D, Yung YL (2007) Lorenz energy cycle of the global 
494 atmosphere based on reanalysis datasets. Geophys Res Lett. doi: 10.1029/2007GL029985

495 Livezey RE, Dutton JA (1976) The entropic energy of geophysical fluid systems. Tellus. doi:

$496 \quad 10.1111 / j .2153-3490.1976 . t b 00662 . x$

497 Lorenz EN (1955) Available potential energy and the maintenance of the general circulation.

498 Tellus. doi: 10.1111/j.2153-3490.1955.tb01148.x

499 Lorenz EN (1967) The natural and theory of the general circulation of the atmosphere. World 500 Meteorological Organization, 161pp.

501 Lorenz, E. N. (1978). Available energy and the maintenance of a moist circulation. Tellus, 30(1), $502 \quad 15-31$.

503 Lucarini V, Fraedrich K, Ragone F (2011) New Results on the Thermodynamical Properties of 504 the Climate System. arXiv preprint arXiv:1002.0157.

505 Marques CA, Rocha A, Corte-Real J, Castanheira JM, Ferreira J, Melo-Gonçalves P (2009) 506 Global atmospheric energetics from NCEP-Reanalysis 2 and ECMWF-ERA40 Reanalysis. 507 International Journal of Climatology. doi: 10.1002/joc.1704

508 Marques CAF, Rocha A, Corte-Real J (2010) Comparative energetics of ERA-40, JRA-25 and 509 NCEP-R2 reanalysis, in the wave number domain. Dynamics of Atmospheres and Oceans. doi: $510 \quad 10.1016 /$ j.dynatmoce.2010.03.003

511 Marques CAF, Rocha A, Corte-Real J (2011) Global diagnostic energetics of five state-of-the-art 512 climate models. Climate dynamics. doi: 10.1007/s00382-010-0828-9

513 Oort AH, and Peixóto JP, 1974: The annual cycle of the energetics of the atmosphere on a 
514 planetary scale. J Geophys Res. doi: 10.1029/JC079i018p02705

515 Oort AH, Peixóto JP (1976) On the variability of the atmospheric energy cycle within a 5-year 516 period. J Geophys Res. doi: 10.1029/JC081i021p03643

517 Ozawa H, Ohmura A, Lorenz RD and Pujol T (2003) The second law of thermodynamics and the 518 global climate system: a review of the maximum entropy production principle. Rev Geophys. doi: $519 \quad 10.1029 / 2002 R G 000113$

520 Paltridge GW (1975) Global dynamics and climate - a system of minimum entropy exchange. Q $521 \quad$ J R Meteorol Soc. doi: 10.1002/qj.49710142906

522 Paltridge GW (2001) A physical basis for a maximum of thermodynamic dissipation of the 523 climate system. Q J R Meteorol Soc. doi: 10.1002/qj.49712757203

524 Pauluis O, Held IM (2002a) Entropy Budget of an Atmosphere in Radiative-Convective 525 Equilibrium. Part I: Maximum Work and Frictional Dissipation. J Atmos Sci. doi:10.1175/1520$526 \quad 0469(2002) 059<0125:$ EBOAAI $>2.0 . C O ; 2$

527 Pauluis O and Held IM (2002b) Entropy Budget of an Atmosphere in Radiative-Convective 528 Equilibrium. Part II: Latent Heat Transport and Moist Processes. J Atmos Sci. doi:10.1175/1520$529 \quad 0469(2002) 059<0140:$ EBOAAI $>2.0 . C O ; 2$

530 Peixoto JP, and Oort AH (1992) Physics of climate. American institute of physics, 520pp.

531 Peixoto JP and Oort AH, De Almeida M, Tomé A (1991) Entropy budget of the atmosphere. J 532 Geophys Res. doi: 10.1029/91JD00721

533 Pauluis O (2007) Sources and Sinks of Available Potential Energy in a Moist Atmosphere. J. 
534 Atmos. Sci. doi:10.1175/JAS3937.1

535 Prigogine I (1962) Introduction to non-equilibrium thermodynamics. Jonh Wiley \& Sons, NY.

536 Rienecker M, et al (2007) The GEOS-5 data assimilation system-Documentation of versions

537 5.0.1 and 5.1.0. NASA GSFC, Tech. Rep. Series on Global Modeling and Data Assimilation, 538 NASA/TM-2007-104606, Vol. 27.

539 Randel WJ, Wu F, Gaffen DJ (2000) Interannual variability of the tropical tropopause derived 540 from radiosonde data and NCEP reanalyses. J Geophys Res. doi: 10.1029/2000JD900155

541 Romps DM (2008) The dry-entropy budget of a moist atmosphere. J Atmos Sci. 542 doi:10.1175/2008JAS2679.1

543 Santer BD, et al. (2004) Identification of anthropogenic climate change using a second 544 generation reanalysis. J Geophys Res. doi:10.1029/2004JD005075.

545 Simmons AJ, et al. (2004) Comparison of trends and low-frequency variability in CRU, ERA-40, 546 and NCEP/NCAR analyses of surface air temperature. J Geophys Res. 547 doi:10.1029/2004JD005306.

548 Vinnikov KY, Grody NC, Robock A, Stouffer RJ, Jones PD, Goldberg MD (2006) Temperature 549 trends at the surface and in the troposphere. J Geophys Res. doi: 10.1029/2005JD006392 


\section{Figures:}
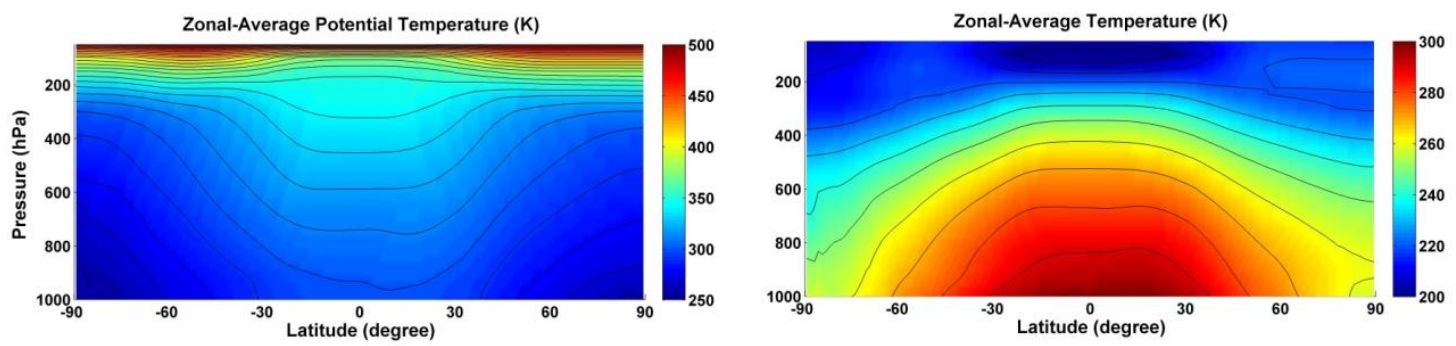

Proposed by Lorenz
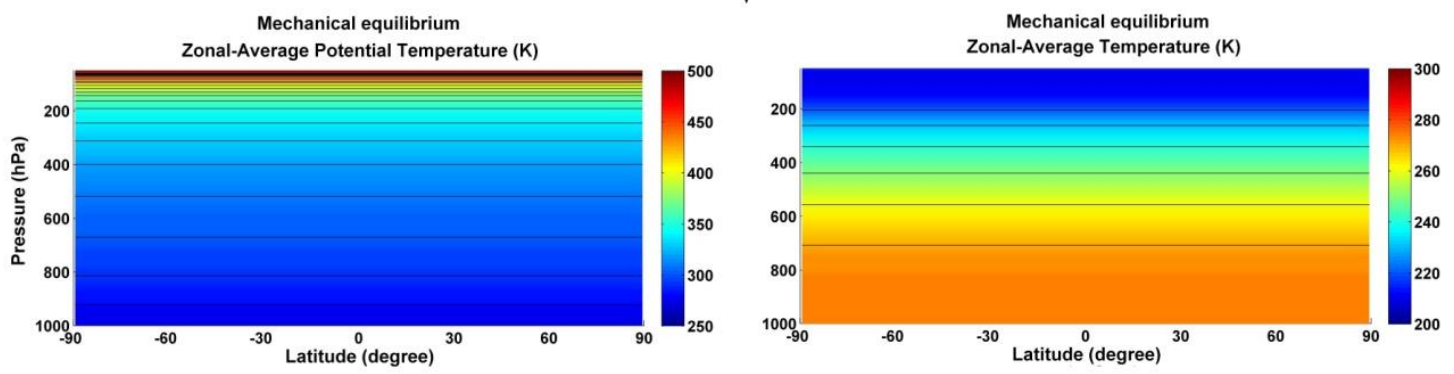

Fig. 1 Schematic illustration of $A P E$. The upper panels present zonal-average potential reference state proposed by Lorenz, again for year 2008. 

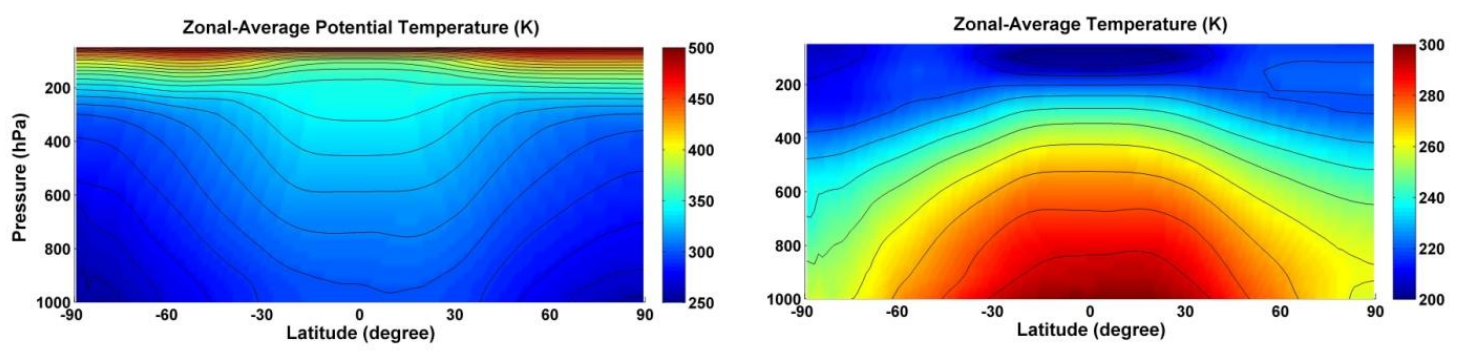

Approaching thermodynamic equilibrium
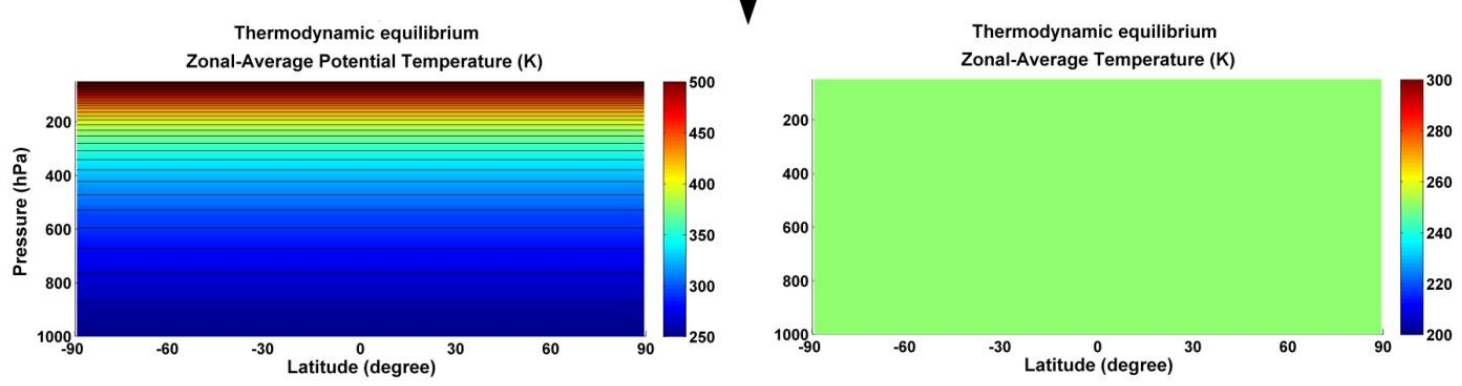

Fig. 2 Schematic illustration of the approach to thermodynamic equilibrium. The upper panels display zonal-average potential temperatures, $\theta$, and zonal-average temperatures, $T$, for year

571 2008. The lower panels indicate zonal-average potential temperatures, $\theta$, and zonal-average

572 temperatures, $T$, for the thermodynamic equilibrium state. 


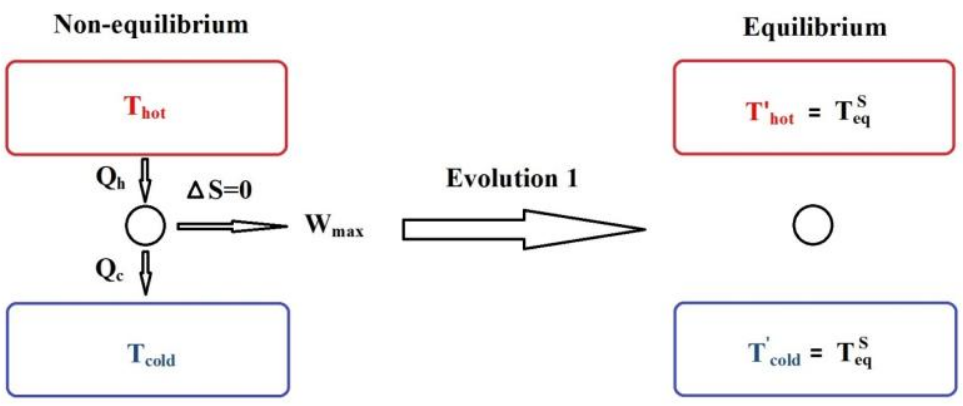

584 Fig. 3 Illustration of $W_{\max }$ produced from a non-equilibrium system. Initially, the thermally 585 isolated system is out of equilibrium and can perform a maximum of mechanical work through 586 reversible processes $(\Delta S=0)$. Finally, the system reaches equilibrium at $T_{e q}^{S}$ in which the 587 temperature contrast between its subcomponents has been eliminated.

588

589

590

591

592

593

594

595

596

597 


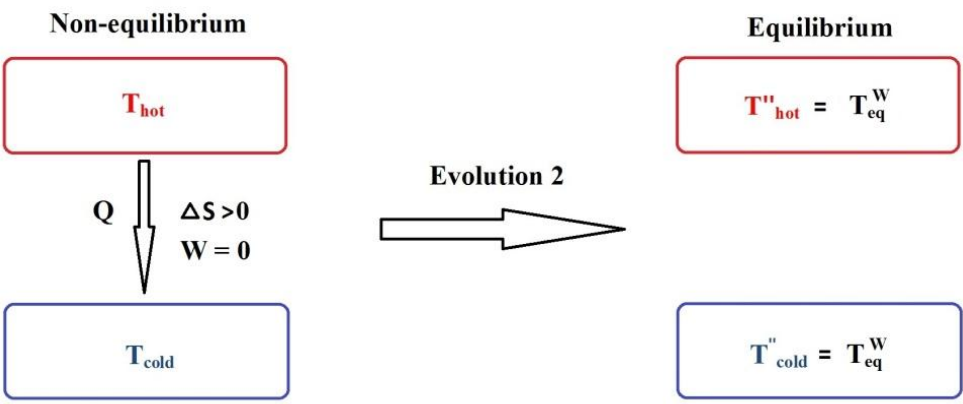

598

599 Fig. 4 Illustration of $(\Delta S)_{\max }$ for the entire non-equilibrium system. Initially, the thermally 600 isolated system is energetic and out of equilibrium. There is a flux of energy $Q$ from the high 601 temperature component at $T_{\text {hot }}$ to the low temperature component at $T_{\text {cold }}$. As heat transfer 602 continues, the system reaches thermal equilibrium at $T_{e q}^{W}$ in which the temperature contrast 603 between its subcomponents has been eliminated.

604

605

606

607

608

609

610

611

612

613 


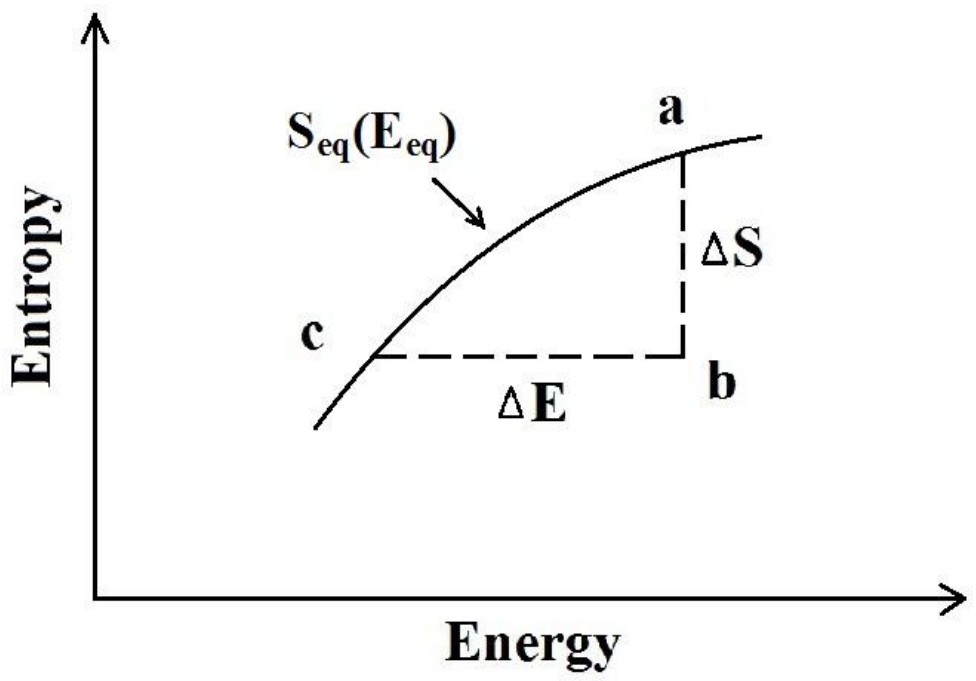

615 Fig. 5 Schematic illustration of the evolution of maximum work and maximum entropy increase 616 in an Entropy-Energy Diagram.

617

618

619

620

621

622

623

624

625

626

627

628

629

630 


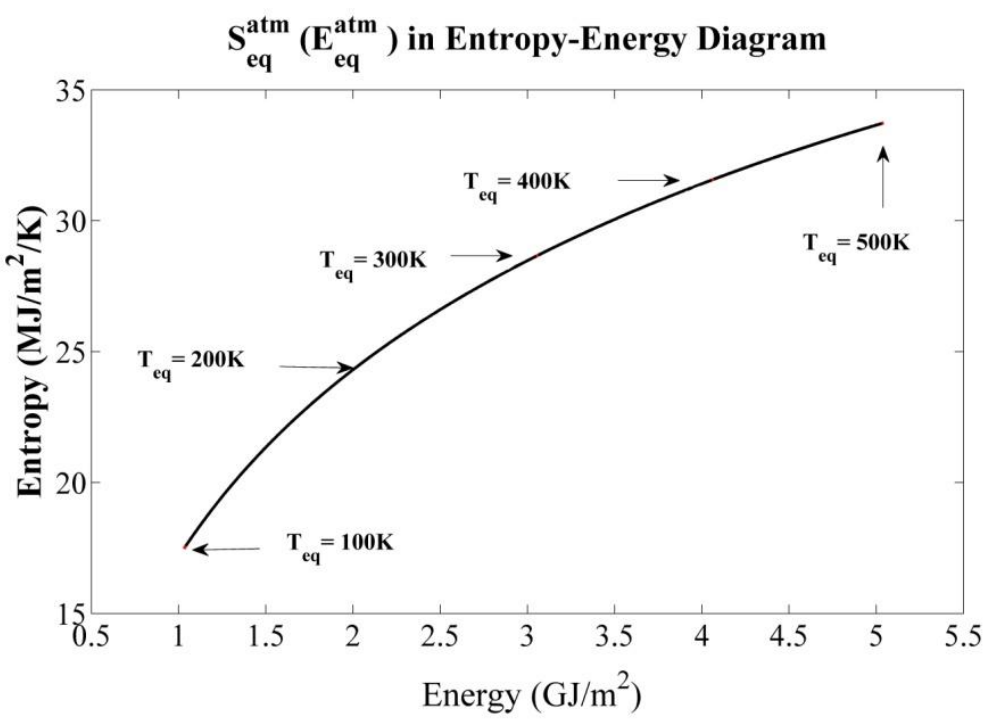

632 Fig. 6 The behavior of the function $S_{e q}^{a t m}\left(E_{e q}^{a t m}\right)$ with $T_{e q}$ increasing from $100 \mathrm{~K}$ to $500 \mathrm{~K}$.

643

644

645

646 


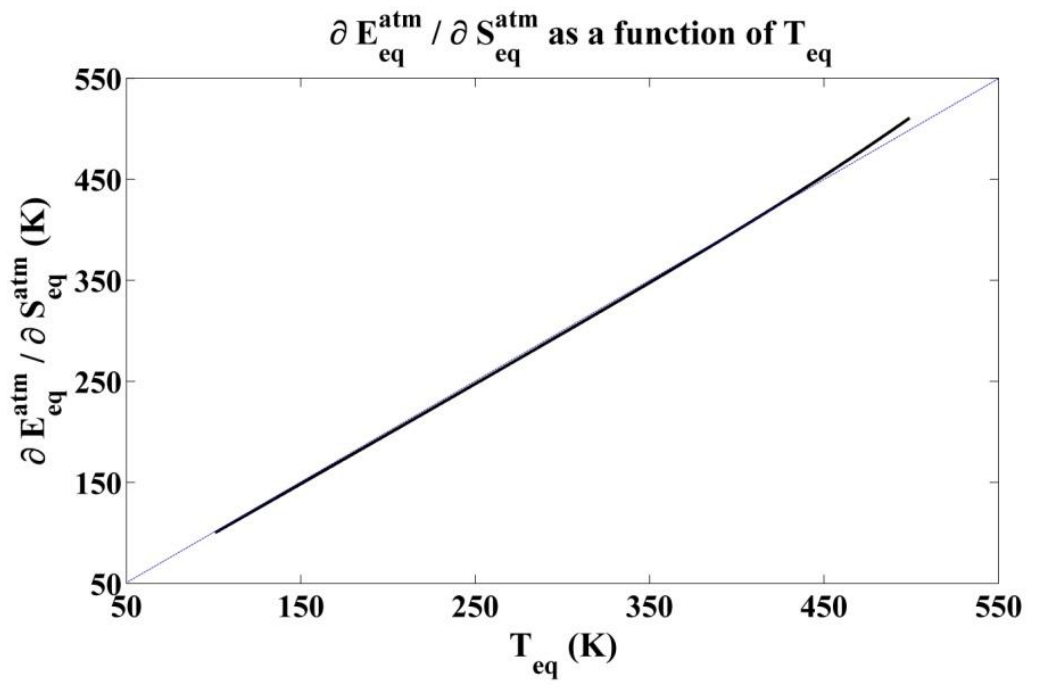

648 Fig. 7 The behavior of the gradient $\partial S_{e q}^{a t m} / \partial E_{e q}^{a t m}$ with $T_{e q}$ ranging from $100 \mathrm{~K}$ to $500 \mathrm{~K}$.

649

650

651

652

653

654

655

656

657

658

659 


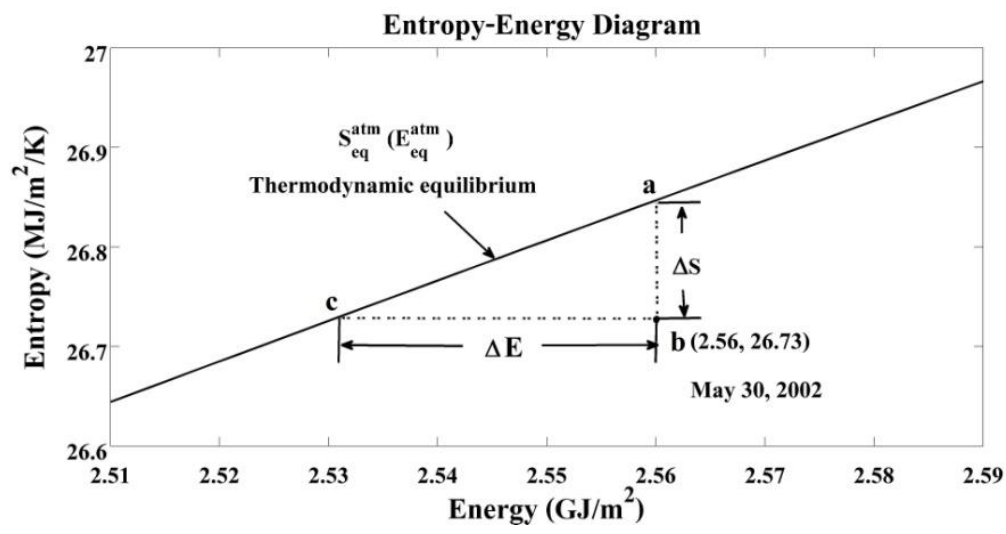

661 Fig. 8 The thermodynamic condition, ( $\left.E^{a t m}, S^{a t m}\right)$, of the atmosphere on May 30, 2002

662 displayed in an Entropy-Energy Diagram. The $\Delta E$ in the figure represents the maximum work,

$663 W_{\text {max }}$, that can be performed in a thermally reversible process; $\Delta S$ represents the maximum 664 increase in entropy, $(\Delta S)_{\max }$, that can arise in a thermally irreversible process with zero work.

665

666

667

668

669

670

671

672

673 


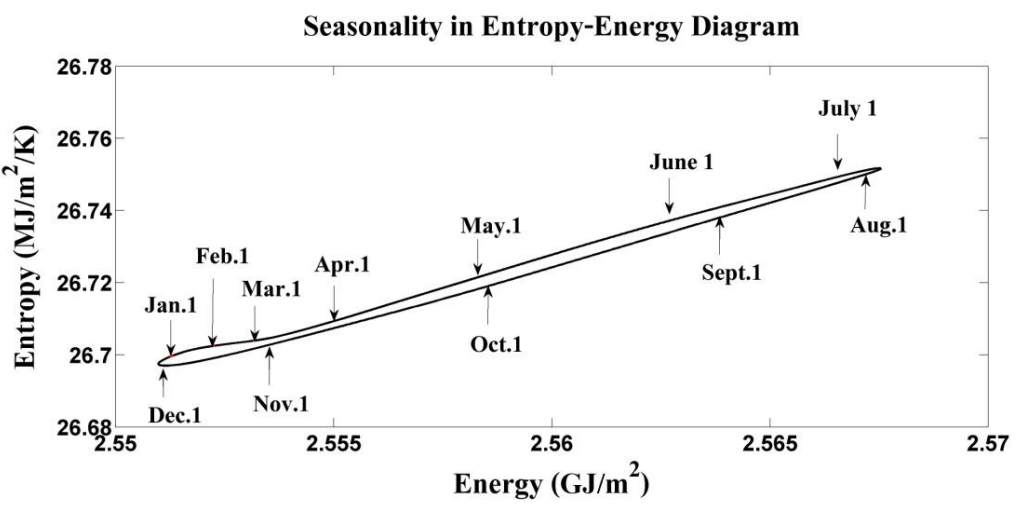

675 Fig. 9 The seasonality of the thermodynamic conditions, $\left(E^{a t m}, S^{a t m}\right)$, of the atmosphere in an 676 Entropy-Energy Diagram.

677

678

679

680

681

682

683

684 


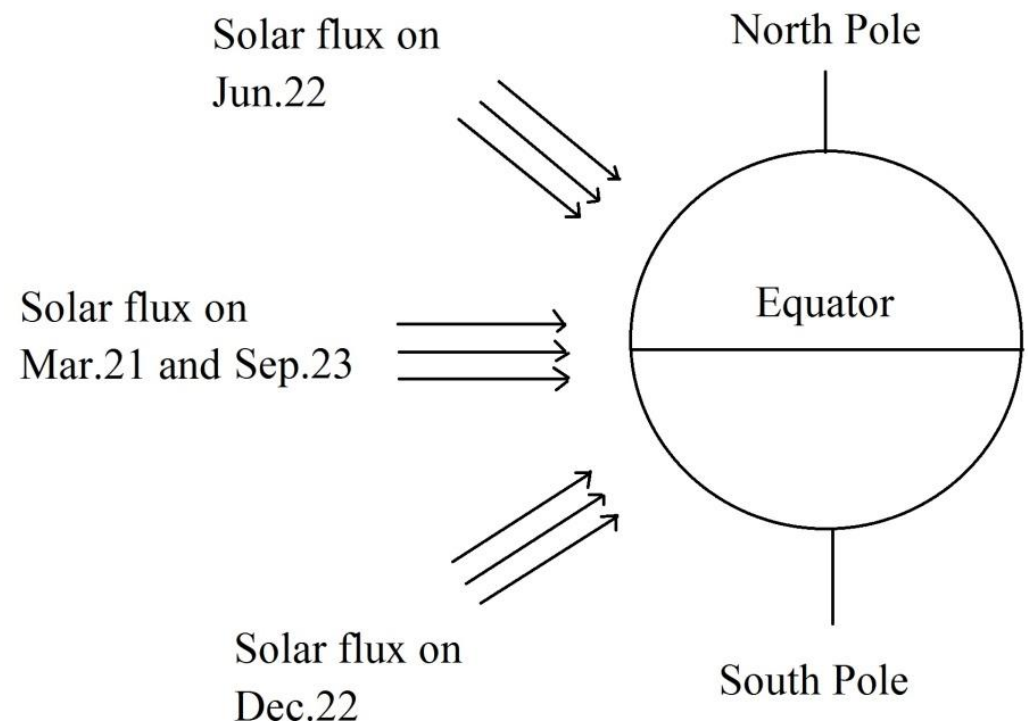

685

686

Fig. 10 Schematic illustration of solar radiation.

687

688

689

690

691 

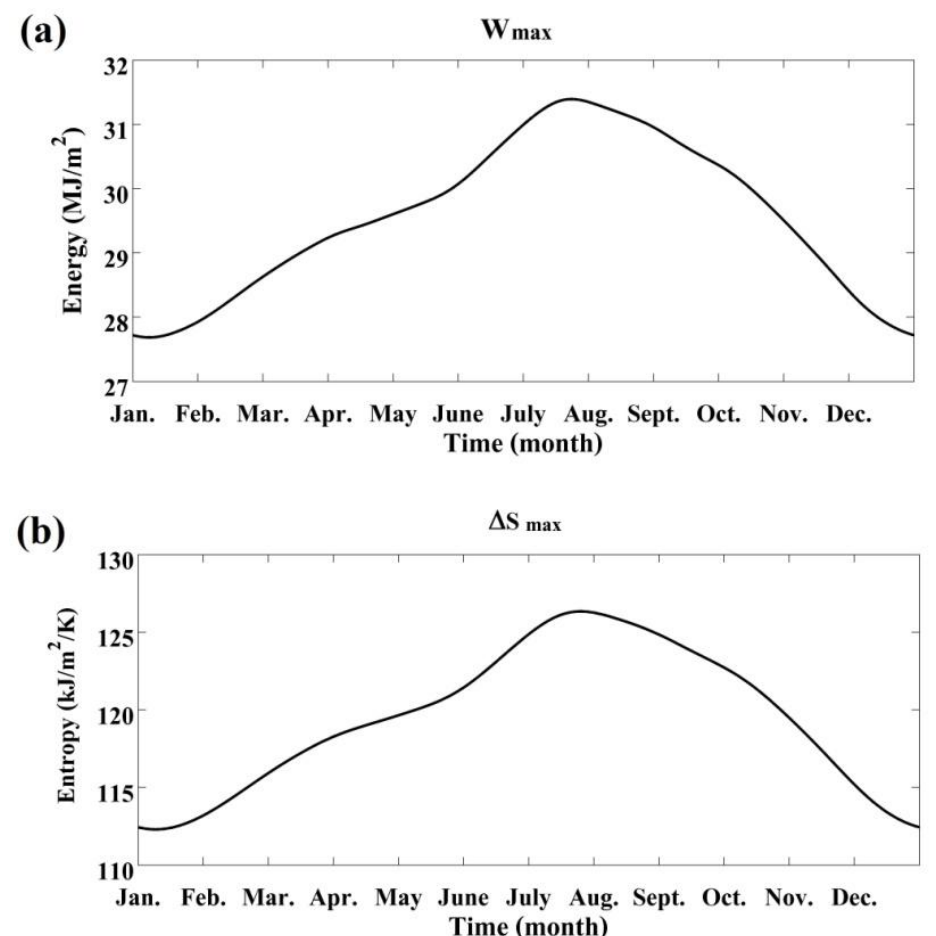

692

693 Fig. 11 The seasonalities of $W_{\max }$ and $(\Delta S)_{\max }$ based on an average of data for the past 32 years.

695

696

697

698

699

700 
701

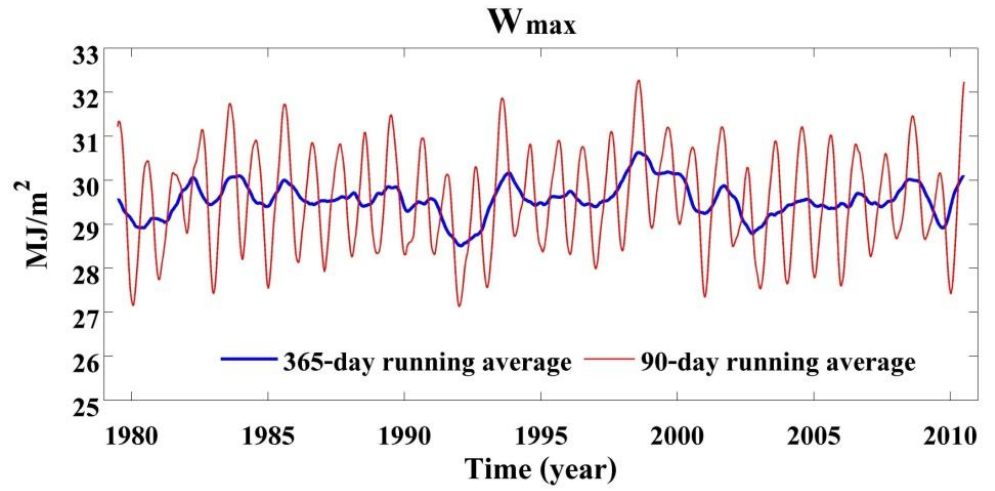

702 Fig. 12 Variation of $W_{\max }$ from January 1979 to December 2010.

703

704

705

706

707

708

709

710

711

712

713

714 


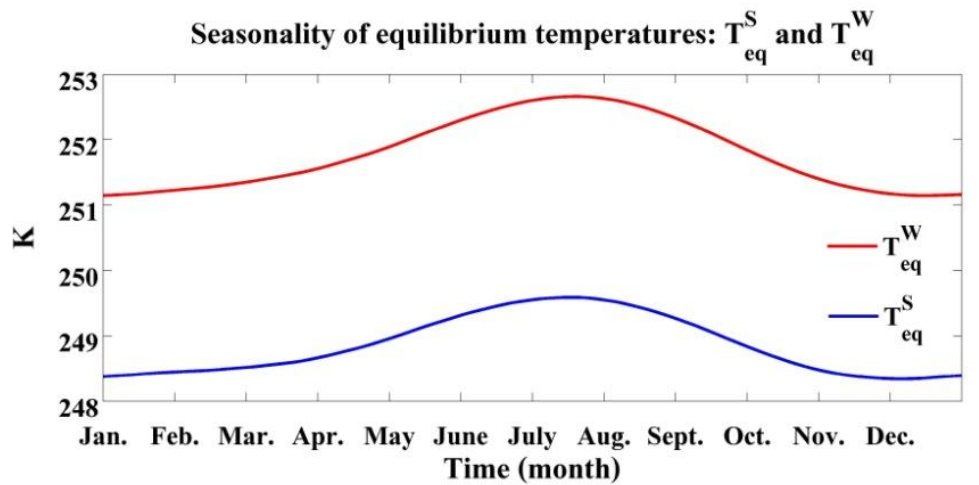

716 Fig. 13 The seasonalities of the equilibrium temperatures, $T_{e q}^{S}$ and $T_{e q}^{W}$, based on an average of 717 data for the past 32 years.

718

719

720

721

722

723

724

725

726

727

728

729

730

731 


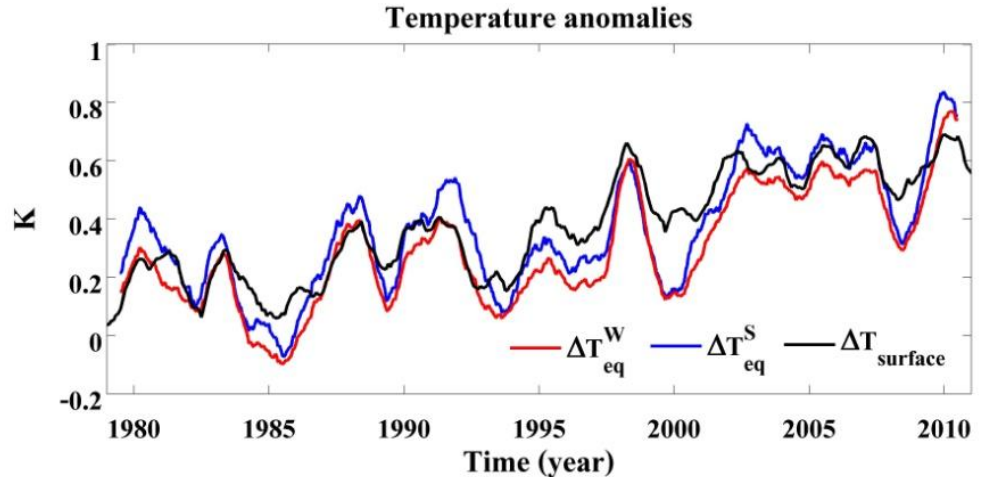

733 Fig. 14 Variation of $\Delta T_{e q}^{S}, \Delta T_{e q}^{W}$ and $\Delta T_{\text {surface }}$ from January 1979 to December 2010. 


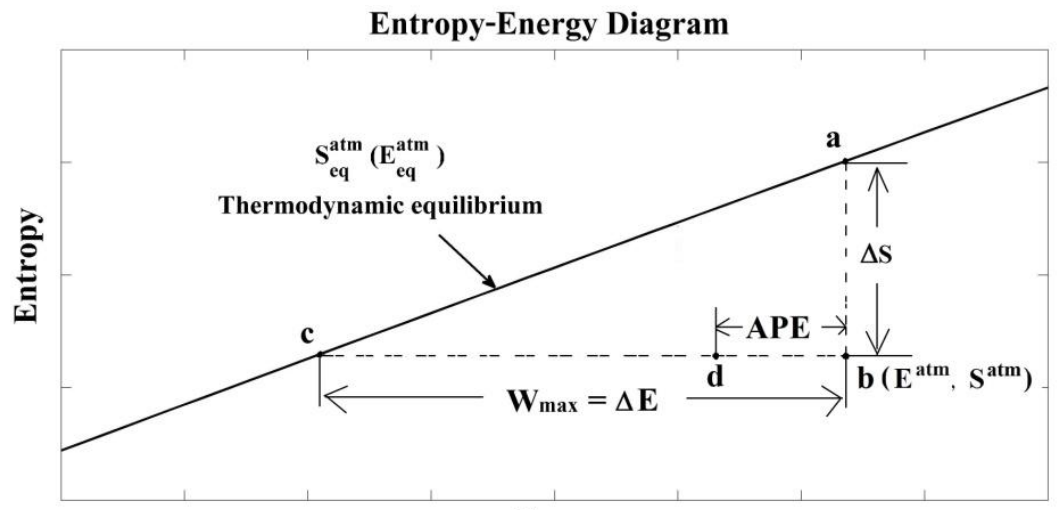

749 Fig. 15 Schematic illustration of the relationship between $A P E$ and $W_{\max }$. The distance between

$750 \quad b$ and $d$ represents $A P E$, and the distance between $b$ and $c$ represents $W_{\text {max }}$.

751

752

753

754

755

756

757

758

759

760

761

762 

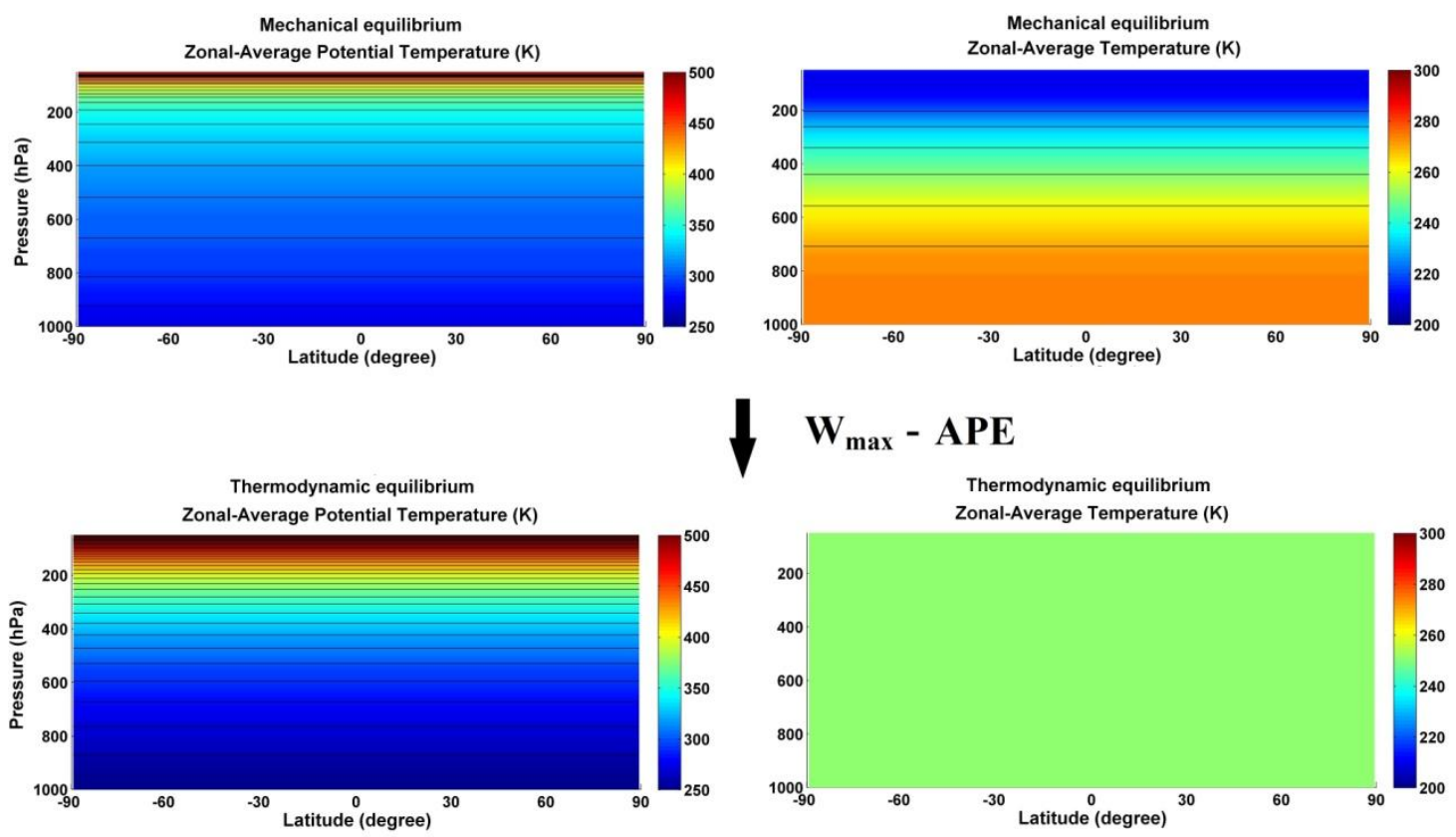

764 Fig. 16 Schematic illustration of $\left(W_{\max }-A P E\right)$. The upper panels display zonal-average

765 potential temperatures, $\theta$, and zonal-average temperatures, $T$, for the associated reference state 766 proposed by Lorenz. The lower panels present zonal-average potential temperatures, $\theta$, and 767 zonal-average temperatures, $T$, for the associated thermodynamic equilibrium state. 